\title{
NF-кB Inhibitor IMD-0354 Targets Human Non-Small Cell Lung Cancer Stem Cells and Combined with Chemotherapy Reduces Multidrug Resistance
}

\author{
Azucena Gomez-Cabrero ${ }^{1 *}$, Wolfgang Wrasidlo² and Ralph A. Reisfeld 1 \\ ${ }^{1}$ Department of Immunology and Microbial Sciences, The Scripps Research Institute, La Jolla, California, USA \\ ${ }^{2}$ Moores Cancer Center, University of California, San Diego, California, USA
}

\begin{abstract}
Most lung cancer patients are diagnosed at an advanced stage, when prognosis is poor. Multidrug resistance and tumor recurrence have been major reasons for these patients to succumb to the disease. Recent evidence points to cancer stem cells as being responsible for multidrug resistance and tumor repopulation as a result of their increased drug efflux and other stem cell-like properties. Thus, recent efforts have focused on targeting these cancer stem cells. Here, we combined liposomal nanoparticles targeted with a legumain inhibitor as a safe vehicle for drug delivery to the tumor microenvironment with Doxorubicin, a common chemotherapeutic agent that targets bulk cancer cells, and IMD-0354, an inhibitor of NF-kB targeting cancer stem cells. IMD-0354 decreased side populations, $A B C$ transporters, stem-like and apoptosis resistance genes, and colony formation of human non-small cell lung cancer cells. In addition, IMD-0354 also had a cytotoxic effect on non-cancer stem cells and increased their apoptosis. The targeted delivery method used previously in syngeneic mouse models enhanced drug delivery under hypoxia, a hallmark of the tumor microenvironment, but not under normoxia. Further, such targeted delivery reduced in vivo tumor burden in an aggressive model of human non-small cell lung cancer xenografts. Targeting of both bulk tumor cells and cancer stem cells with IMD-0354 as an adjuvant for chemotherapy are likely to reduce multidrug resistance and tumor recurrence, and thereby significantly reduce patient death from non-small cell lung cancer.
\end{abstract}

Keywords: NF- $\mathrm{BB}$; Inhibitor; NSCLC, Human; Lung; Cancer; Targeting; Nanoparticles; Therapy; Cancer stem cells

Abbreviations: 3D: Three-Dimensional; A549Luc: Firefly Luciferase Expressing A549 Cells; AAALAC: Association for Assessment and Accreditation of Laboratory Animals Care; ABC transporters: ATP-binding Cassette Transporters; ATP: Adenosine Triphosphate; BSA: Bovine Serum Albumin; Cis: Cisplatin; $\mathrm{cm}^{2}$ : Square Centimeters; $\mathrm{CoCl}_{2}$ : Cobalt Chloride; CSCs: Cancer Stem Cells; Cyt.: Cytosolic; DOPE: 1,2-dioleoyl-sn-glycero-3-phosphoethanolamine; DOPE-PEG: 1,2-dioleoyl-sn-glycero-3-phospho- ethanolamine-N[methoxy(polyethylene glycol)-2000]; DOPC: 1,2-dioleoyl-sn-glycero3-phosphocholine; Dox: Doxorubicin; DMEM: Dulbelco's Minimum Essential Medium; F12K: Kaighn's Modification of Ham's F-12 Medium; FACS: fluorescence activated cell sorting; FBS: fetal bovine serum; FITC: Fluorescein Isothiocyanate; FGF: Fibroblast Growth Factor; FGFb: Fibroblast Growth Factor type b; h: Hour; HEPES: 4-(2-hydroxyethyl)-1-piperazineethanesulfonic acid; $\mathrm{IC}_{50}$ : Inhibitory concentration with a $50 \%$ cytotoxic effect; IKK: I nuclear factor of kappa light polypeptide gene enhancer in B-cells inhibitor kinase; IкBa: Nuclear factor of kappa light polypeptide gene enhancer in B-cells inhibitor, alpha; MDR: Multidrug resistance; mg: Milligram; $\mu \mathrm{g}$ : Microgram; $\mu \mathrm{l}$ : Microliter; ml: Milliliter; $\mu \mathrm{M}$ : Micromolar; mM: Millimolar; MTT: 3-(4,5-dimethylthiazol-2-yl)-2,5-diphenyltetrazolium bromide; Mtx: Mitoxantrone; NF-кB: Nuclear factor kappa-light-chain-enhancer of activated B cells; NIH: National Institutes of Health; nM: Nanomolar; non-CSCs: non-Cancer Stem Cells; non-SP: non-Side Population; NP: Nanoparticles; NSCLC: Non-small cell lung cancer; Nuc.: Nuclear; OD: Optical Density; PBS: Phosphate Buffered Solution; PI: Propidium iodide; p/s: photons/second; RIPA: Radioummunoprecipitation assay buffer; RPMI: Roswell Park Memorial Institute medium; sec: second; SP: Side Population; sr: steradian; TME: Tumor microenvironment; tNP: Targeted nanoparticles; tNP-Dox: Dox loaded tNPs; tNPDox-IMD-0354: Dox and IMD-0354 loaded tNPs; tNP-IMD-0354:
IMD-0354 loaded tNPs; TRDRP: Tobacco-Related Disease Research Program.

\section{Introduction}

Lung cancers are not as frequently tested as breast cancer. For this and other reasons, most patients diagnosed with lung cancer are already at an advanced stage of disease. As a result, lung cancer is the second most commonly diagnosed malignancy among Americans, first among gender-independent cancers, and first in cancer related deaths [1]. Although during the last few years, death rates from lung cancer have been decreasing, they still remain alarmingly high. Therefore, in addition to better diagnostic tools, efficient therapies are urgently needed, especially those with efficacy in treating aggressively invading lung cancers.

In addition to the advanced stage of lung cancer at time of diagnosis, treatments with radio- and/or chemotherapy commonly make the tumors develop radiation resistance and multiple drug resistance

*Corresponding author: Azucena Gomez-Cabrero, Department of Immunology and Microbial Sciences, The Scripps Research Institute, La Jolla, California 92037 USA, Tel: (+1) 858.784.8109 / (+1) 858.232.3207; Fax: (+1) 858.784.2708; E-mail: agomezcabrero@hotmail.com; agomezc@scripps.edu

Received August 06, 2013; Accepted September 16, 2013; Published September 19,2013

Citation: Gomez-Cabrero A, Wrasidlo W, Reisfeld RA (2013) NF-kB Inhibitor IMD0354 Targets Human Non-Small Cell Lung Cancer Stem Cells and Combined with Chemotherapy Reduces Multidrug Resistance. J Cancer Sci Ther 5: 300-312. doi:10.4172/1948-5956.1000220

Copyright: (C) 2013 Gomez-Cabrero A, et al. This is an open-access article distributed under the terms of the Creative Commons Attribution License, which permits unrestricted use, distribution, and reproduction in any medium, provided the original author and source are credited. 
(MDR) and tumor recurrence, which ultimately lead to patients' death. Therefore, targeting MDR and preventing tumor recurrence should prevent many of those casualties. An emerging hypothesis places cancer stem cells (CSCs), a subpopulation of cells found in most cancers, as the corner stone of MDR and tumor recurrence, due to their ability to repopulate tumors, efflux chemotherapeutic agents, resist apoptosis and hypoxia, and present other stem-like properties $[2,3]$. This hypothesis also suggests that radio- and chemotherapy fail because they would eliminate only bulk tumor cells, but not CSCs, which survive and allow cancer recurrence. CSCs can be assessed and identified by several means. They are able to form tumors in vivo at a limiting dilution $[4,5]$. CSCs express characteristic cell-surface marker profiles [6-9]. In non-small cell lung cancer (NSCLC), which accounts for $80 \%$ of lung caners [10], CSCs were reported to be enriched in the CD44+ sub-fraction of cells [11], and the combination of stem cell markers CD133 and ABCG2 predicted relapse at stage I NSCLC [12]. Furthermore, CSCs were able to survive in serum free medium and proliferate as cellular tumor-spheres [4]. In addition, populations enriched in CSCs also exhibit increased resistance to chemotherapeutic agents and radiotherapy [13-16].

Since CSCs are an effective target for lung cancer therapy, high throughput screening technologies should be adapted to detect specific toxicity for such a small subpopulation of cells among predominant bulk tumor cells. Time consuming CSC enrichment in samples is impractical due to their instability and enrichment of lung CSCs is rapidly diminished during in vivo propagation [17]. Although specific surface markers have been used for identification of CSCs in heterogeneous samples, their heterogeneity among cell lines, patient samples and type of cancers remains a limiting factor for high throughput screening $[11,18,19]$. However, screening of CSCs based on a functional assay would have a more reliable applicability independently from the heterogeneity of surface markers.

We recently adapted a functional cellular assay that allows CSCs screening in a high throughput setting, based on the CSCs ability to efflux dyes and chemotherapeutic agents by overexpressed $\mathrm{ABC}$ transporters. Therefore, when cells are incubated with Hoechst 33342 dye, bulk tumor cells accumulate the dye, but CSCs efflux it and segregate as a subpopulation with lower intensity for this dye, also called side population (SP). One of the compounds found to decrease SP of CSCs with this assay was IMD-0354, an inhibitor of the NF$\kappa \mathrm{B}$ pathway, which was initially described to have cardio-protective properties in ischemia/reperfusion injury and anti-inflammatory effects [20]. The NF- $\kappa \mathrm{B}$ pathway has traditionally been linked to inflammation, but it also plays a role in proliferation, anti-apoptosis, angiogenesis and immune tolerance in the tumor microenvironment (TME). In fact, NF- $\kappa B$ can be found constitutively active, in the nucleus of many cancer cells due to a chronic stimulation of the IKK pathway or mutations on IkBa [21-23]. Furthermore, NF- $\mathrm{kB}$ pathway inhibition with IMD-0354 has been reported to have a cytotoxic effect on bulk tumor cells, suggesting its applicability for cancer treatment [24].

Doxorubicin (Dox) is a common chemotherapeutic drug used to treat several types of cancer, including lung cancer. However, side effects and off target toxicity of most chemotherapeutic agents limit their dosing and efficacy. This is especially true for Dox, since its acute cardiac toxicity makes it a high risk option [25]. Clinical trials using Dox encapsulated into liposomal nanoparticles proved to reduce Dox's heart toxicity, but the absence of a specific targeting method of such liposomal Dox does not protect other organs, like liver, from toxicity [26]. In this regard, we recently developed a targeting strategy that uses
R11-a as a ligand that binds covalently to legumain, a protein exposed on the cell membrane in the TME [27]. Legumain is the only mammalian asparaginyl endopeptidase, which is overexpressed on tumorassociated macrophages and on tumor cells under hypoxic stress [2831]. Interestingly, legumain expression increased cell migration and invasion in vitro, and correlated with poor prognosis and malignancy [32-34]. Furthermore, legumain activated prodrugs suppressed tumor growth and metastasis without toxicity [35]. In agreement with these reports, we previously demonstrated that using R11-a for legumaintargeting dramatically improved liposomal nanoparticles (NP) drug delivery to solid breast tumors without off target toxic effects [36]. Given that legumain is expressed in solid tumors of different origin, we think its inhibitor R11-a can be used to direct NPs loaded with drugs to the TME of solid lung tumors.

Here, we hypothesize that MDR can be overcome by sensitizing CSCs to chemotherapy with targeted molecular therapeutics. We describe the effects of the NF-kB inhibitor, IMD-0354, on CSCs of human NSCLC cells and its potential adjuvant properties to enhance chemotherapeutic tumor cytotoxicity. For in vivo delivery to the TME, we developed a novel loading strategy to encapsulate IMD-0354 into legumain-targeted NPs, and we demonstrated that this novel combination therapy with Dox and IMD-0354 improved the antitumor effects of Dox in a mouse model of human NSCLC xenograft mimicking an aggressively progressing lung cancer in athymic mice. In summary, the combination of sensitizing of CSCs to chemotherapy, reducing off target effects by drug encapsulation and targeting drug delivery to the TME will potentially reduce NSCLC recurrence and improve prognosis of patients with this fatal disease

\section{Material and Methods}

\section{Cells and drugs}

The human NSCLC A549 (NCIA549, ATCC ${ }^{\circledR}$ CCL185) cell line was purchased from ATCC (Manassas, VA). The A549Luc firefly luciferase expressing human NSCLC cell line was provided by Dr. Edward Graves (Stanford University School of Medicine) [37]. The A549 and A549Luc cell lines were maintained in F12K medium (Gibco), supplemented with $10 \%$ FBS and 1\% HEPES. Cells were tested for negativity of mycoplasma by the in-house Center for Antibody Development and Production core. IMD-0354 was purchased from Tocris Bioscience (Bristol, UK); Dox from LC Laboratories (Woburn, MA); $\mathrm{CoCl}_{2}$, mitoxantrone and cisplatin from Sigma-Aldrich (St. Louis, MO).

\section{Viability assay (MTT)}

For viability assays with MTT, cells were incubated with $0.5 \mathrm{mg} /$ $\mathrm{ml}$ thiazolyl blue tetrazolium bromide (Alfa Aesar, Ward Hill, MA) for 10-60 min; the formazan product was then solubilized in ethanol and its $\mathrm{OD}$ at $570 \mathrm{~nm}$ was measured on a plate reader spectrophotometer.

\section{Flow cytometry}

For analysis of the side population (SP) phenotype, cells were stained with $1 \mathrm{mg} / \mathrm{ml}$ of Hoechst 33342 dye for $1 \mathrm{~h}$ in DMEM medium containing $2 \%$ FBS and $10 \mathrm{mM}$ HEPES; cells were then washed twice with PBS and detached with CellStripper (Cellgro, Manassas, VA) for $20 \mathrm{~min}$. and collected with HBSS containing 2\% FBS, 10 mM HEPES and $0.625 \mu \mathrm{g} / \mathrm{ml}$ propidium iodide (PI). Hoechst dye was excited at $407 \mathrm{~nm}$ by a trigon violet laser and its dual wavelengths were detected using 450/40 (Hoechst 33342-Blue) and 695/40 (Hoechst 33342Red) filters. PI was excited at $488 \mathrm{~nm}$ using an octagon blue laser and fluorescence detected by a $675 / 20$ filter. Dead cells were excluded by 
gating on forward and side scatter and by eliminating PI-positive populations [38].

Apoptosis was analyzed with Aposcreen Annexin V-FITC following manufacturer's instructions (SouthernBiotech, Birmingham, $\mathrm{AL})$. For analysis of legumain expression, immunocytochemistry was performed with an anti-legumain antibody (Novus Biologicals, Littleton, CO) and anti-mouse-FITC (Southernbiotech, Birmingham, $\mathrm{AL}$ ). Cells were analyzed by LSR-II FACS (Becton Dickinson, Franklin Lakes, NJ) and data analyzed with FlowJo software (Tree Star, Inc., Ashland, OR).

\section{Colony formation}

For 3D colony formation, cells were plated as 10,000 cells/well in 6-well ultra-low attachment plates, and cultured with MDEM/F12 (1:1) medium with L-glutamine and HEPES, supplemented with $1 \times 327,20$ $\mathrm{ng} / \mathrm{ml} \mathrm{FGF}$ and $20 \mathrm{ng} / \mathrm{ml} \mathrm{bFGF}$. Every day, the drug or vehicle was added to a final concentration of $1 \mu \mathrm{M}$. Every three days, fresh medium was added. Colonies were counted as groups of three or more cells.

\section{Western blots}

Protein extracts were prepared as previously described [39]. Whole extracts were obtained with RIPA buffer; cytosolic and nuclear extract were prepared as previously described [40]. Western blots were done as previously described $[39,41]$ and probed with the following antibodies: beta-actin, MDR1, ABCG2, Nanog, Oct4, Sox2, Survivin (all Santa Cruz Biotechnology, Dallas, TX) and legumain (Novus Biologicals, Littleton, CO).

\section{Nanoparticle formulation}

Synthesis of the legumain-specific inhibitor RR-11a was previously described [42]. For conjugation to lipids, we modified the ligand RR11a by introducing a NHS ester group for coupling to the amino group of DOPE. Phospholipids (Avanti Polar Lipids, Alabaster, AL) were dissolved in chloroform. RR-11a was conjugated to 1,2-dioleoyl-sn-glycero-3-phosphoethanolamine (DOPE) using triethylamine as a catalyst. The resulting compound was combined with 1,2-dioleoyl-sn-glycero-3-phosphocholine (DOPC), DOPE, cholesterol, and 1,2-dioleoyl-sn-glycero-3-phospho-ethanolamine-N[methoxy(polyethylene glycol)-2000], DOPE- PEG, at molar ratios of 1.1:6.7:6.7:2.2:1, as previously described [43]. Dox was loaded into nanoparticles as previously described [27]. IMD-0354 was dissolved in $10 \%$ BSA in PBS pH 7.4, and lipids were dissolved in chloroform and the solvent evaporated to leave a lipid film. IMD-0354/BSA solution was added to this film and the mixture treated as for Dox nanoparticles. The non-encapsulated IMD-0354/BSA solution was removed by separation using sepharose (R) CL-4B (Sigma-Aldrich, St. Louis, MO). All nanoparticles were filter sterilized.

\section{Animal experiments}

Female athymic nu/nu mice were purchased from The Scripps Research Institute Rodent Breeding Facility and housed in an AAALAC accredited facility. All animal procedures were performed in accordance with institutional guidelines pertaining to the humane care of animals and approved by The Scripps Research Institute Animal Care and Use Committee. Mice were injected intravenously with $10^{6}$ A549Luc cells in $100 \mu \mathrm{l}$ PBS on day 0 . Next day, seeding of bioluminescent cancer cells on internal organs was confirmed by in vivo imaging after intraperitoneal injection of firefly D-luciferin potassium salt (Biosynth; Itasca, IL) in PBS. Mice received 6 intravenous injections, at 3-day intervals, of tNP-Dox $(\mathrm{n}=6)$, tNP-IMD-0354 $(\mathrm{n}=10)$, or tNP-Dox-IMD-0354 $(\mathrm{n}=8)$ in $200 \mu \mathrm{l}$ PBS. Control mice $(\mathrm{n}=8)$ received PBS. Tumor burden and progression were followed by in vivo bioluminescence imaging (IVIS200, from Caliper-PerkinElmer, Hopkinton, MA), and body weight was annotated periodically. Mice were sacrificed 24 hours after the final treatment and body weight determined.

\section{Statistical analysis}

The statistical significance of differential findings between experimental groups and controls was determined by 2-tailed Student's t test using Prism software (GraphPad, La Jolla, CA). Results were regarded as significant if $\mathrm{P}$-value $<0.05$.

\section{Results}

\section{Human NSCLC cell lines A549 and A549Luc are resistant to common chemotherapeutic agents}

The A549 cells are derived from a human NSCLC cell line [44]. They are able to produce tumors and metastasis in immunecompromised mouse models in a similar way as that of human NSCLC [45]. A549 cells were treated with Dox at different concentrations for 24 to 72 hours, and their viability analyzed using the cell proliferation/ cytotoxicity assay MTT (Figures 1A-C). In these cells, Dox showed an $\mathrm{IC}_{50}$ (inhibitory concentration with a $50 \%$ cytotoxic effect) in the micromolar range (Figures $1 \mathrm{~A}-\mathrm{C}$; $\mathrm{IC}_{50}=>30.0 \mu \mathrm{M}$ at $24 \mathrm{~h} ; 1.9 \mu \mathrm{M}$ at $48 \mathrm{~h}$; and $1.0 \mu \mathrm{M}$ at $72 \mathrm{~h}$ ), in agreement with prior data [46], and with typical cellular death and apoptotic cell morphology under the microscope proportionally to the cytotoxic effect. Similar results were obtained when these cells were treated with mitoxantrone (Mtx; Figures $2 \mathrm{D}-\mathrm{F} ; \mathrm{IC}_{50}=2.0 \mu \mathrm{M}$ at $24 \mathrm{~h} ; 0.4 \mu \mathrm{M}$ at $48 \mathrm{~h}$; and $0.5 \mu \mathrm{M}$ at $72 \mathrm{~h}$ ). A549 cells treated with cisplatin (Cis) for 24 to $72 \mathrm{~h}$ showed a higher resistance to this drug than to Dox and Mtx, with $\mathrm{IC}_{50}$ in the high micromolar range (Figs. $3 \mathrm{~A}-\mathrm{C}$; $\mathrm{IC}_{50}=>100 \mu \mathrm{M}$ at $24 \mathrm{~h} ; 68 \mu \mathrm{M}$ at $48 \mathrm{~h}$; and $53 \mu \mathrm{M}$ at $72 \mathrm{~h}$ ).

The A549Luc cell line is a firefly luciferase expression clone derived from A549 cells. A549Luc cells showed a similar sensitivity to Dox (Figure $1 \mathrm{D}-\mathrm{F} ; \mathrm{IC}_{50}=>30.0 \mu \mathrm{M}$ at $24 \mathrm{~h} ; 1.2 \mu \mathrm{M}$ at $48 \mathrm{~h}$; and $0.9 \mu \mathrm{M}$ at 72 h) and a slightly higher sensitivity to Mtx (Figure 2D-F; IC $_{50}=0.93 \mu \mathrm{M}$ at $24 \mathrm{~h} ; 0.05 \mu \mathrm{M}$ at $48 \mathrm{~h}$; and $<0.03 \mu \mathrm{M}$ at $72 \mathrm{~h}$ ). A549Luc cells showed a higher sensitivity to Cis compared to parental A549 cells as shown by MTT assay (Figures 3D-F; $\mathrm{IC}_{50}=\approx 11.9 \mu \mathrm{M}$ at $24 \mathrm{~h} ; 1.1 \mu \mathrm{M}$ at $48 \mathrm{~h}$; and $1.0 \mu \mathrm{M}$ at $72 \mathrm{~h}$ ). All together, these results indicated a chemoresistant behavior for both human NSCLC cell lines, similar to the multidrug resistance affecting most NSCLC patients.

\section{Human NSCLC cells contain a subpopulation of CSCs}

Different tests have been applied to prove the presence of CSCs in human NSCLC cells. A fast, marker-independent way to identify CSCs is to stain cells with Hoechst 33342 dye and then analyze their red and blue/violet fluorescence by FACS. CSCs overexpress different drug efflux pumps and are able to exclude the dye, appearing as a side population (SP) with low fluorescence for this dye. However, nonCSCs or bulk tumor cells are unable to efflux the dye as efficiently as CSCs and therefore appear as a non-SP with higher dye fluorescence. SP has been identified as the population that disappears when a drug efflux pump inhibitor is used during staining, such as reserpine or verapamil. Reserpine and other pump inhibitors reduce the ability of CSCs to efflux dye to an extent similar to non-CSCs [38,47]. Human $\mathrm{H} 460$ cells presented distinct SP of cells (Figure 4A; $53.40 \pm 0.59 \%$ cells when compared to $0.13 \pm 0.02 \%$ cells in reserpine treated cells); A549 and A549Luc cells also showed SPs of CSCs (Figures 4B-C; A549: 11.43 

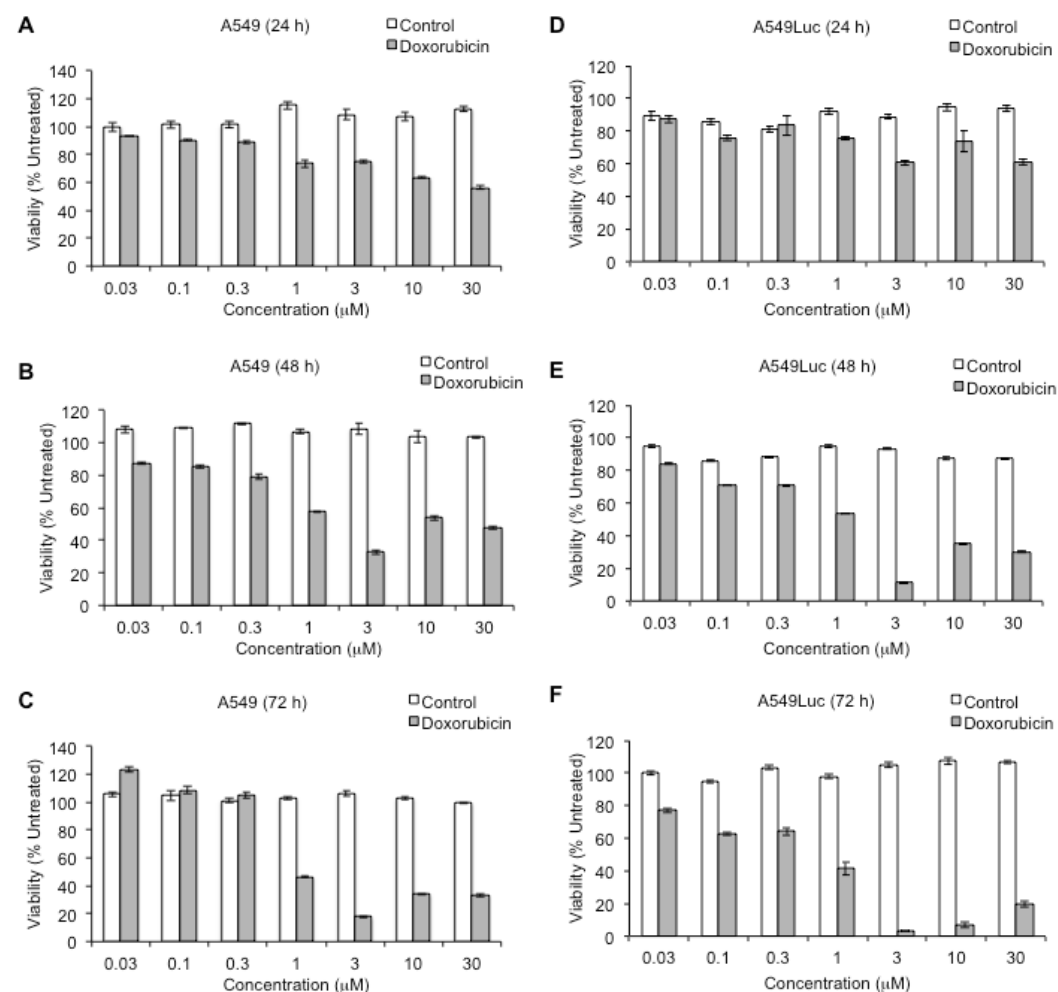

Figure 1: Human NSCLC cells A549 and A549Luc are chemoresistant to Dox. Viability of A549 and A549Luc cells was assessed by MTT assay after treatment with doxorubicin for $24 \mathrm{~h}(\mathrm{~A}$ and $\mathrm{D}), 48 \mathrm{~h}$ (B and $\mathrm{E})$ and $72 \mathrm{~h}(\mathrm{C}$ and $\mathrm{F})$. Data are shown as mean $\pm \mathrm{SEM}$.
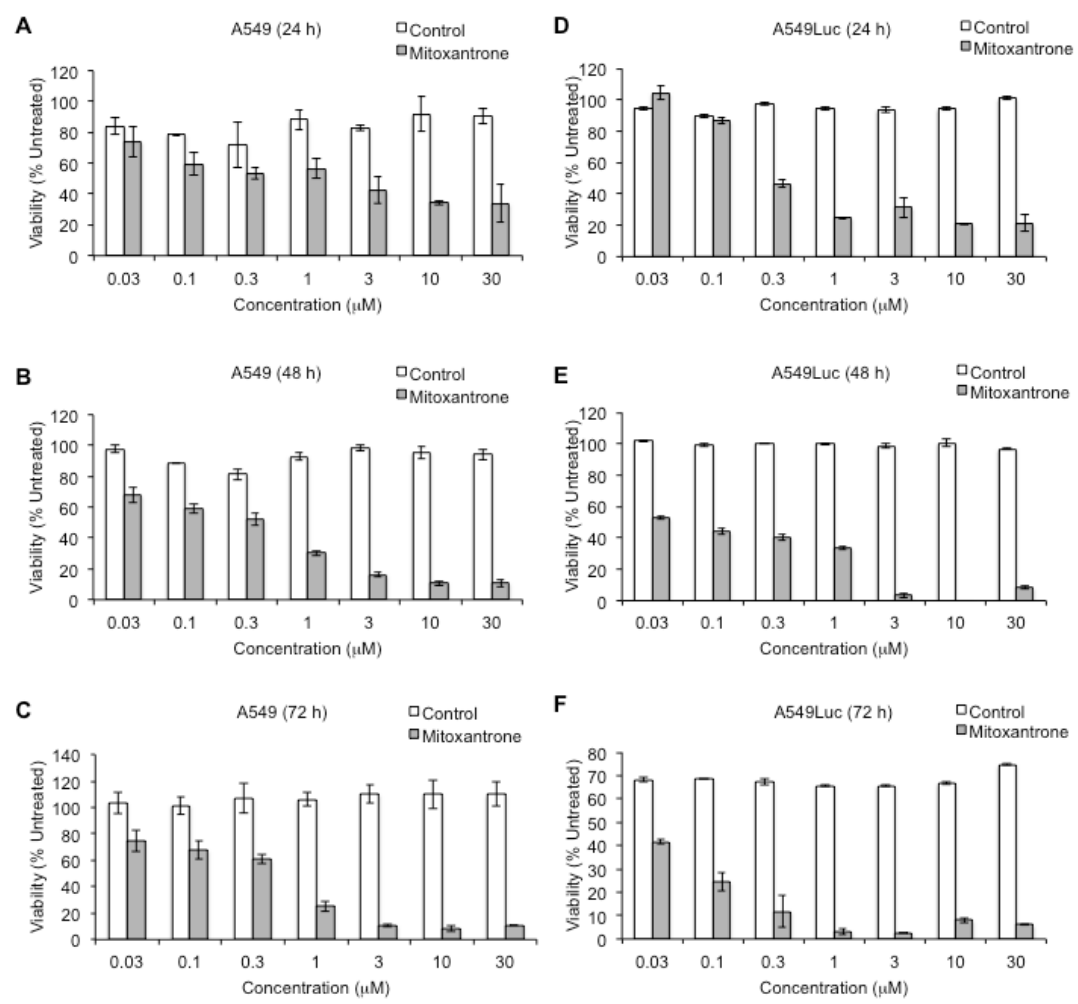

Figure 2: Human NSCLC cells A549 and A549Luc are chemoresistant to Mtx. Viability of A549 and A549Luc cells was assessed by MTT assay after treatment with mitoxantrone for $24 \mathrm{~h}(\mathrm{~A}$ and $\mathrm{D}), 48 \mathrm{~h}(\mathrm{~B}$ and $\mathrm{E})$ and $72 \mathrm{~h}(\mathrm{C}$ and $\mathrm{F})$. Data are shown as mean \pm SEM. 

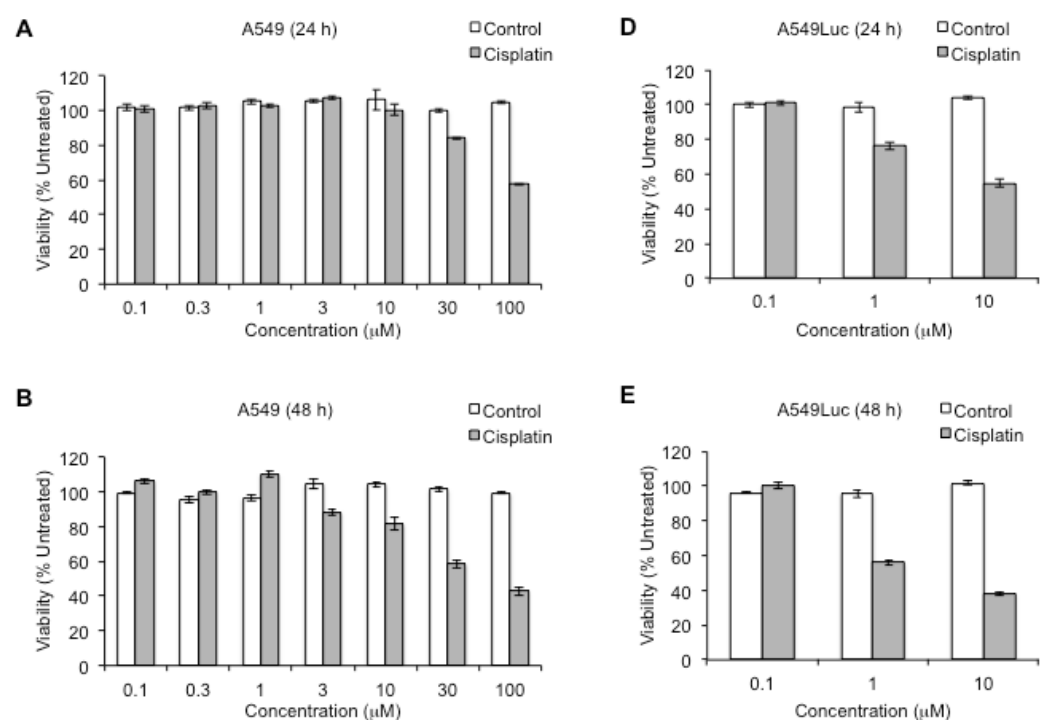

E
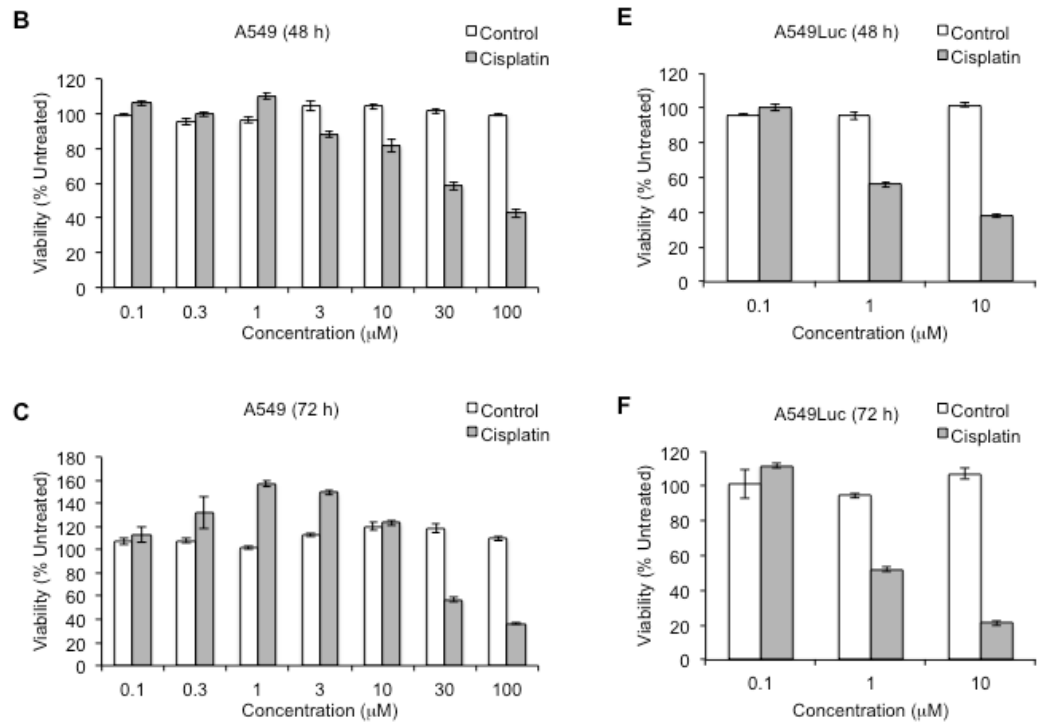

Figure 3: Resistance to cisplatin by A549Luc and parental A549 cells. Viability of A549 cells was assessed by MTT assay after treatment with cisplatin for $24 \mathrm{~h}$ (A), 48 $\mathrm{h}(\mathrm{B})$ and $72 \mathrm{~h}(\mathrm{C})$. Viability of A549Luc was assessed by MTT assay after treatment with cisplatin for $24 \mathrm{~h}(\mathrm{D}), 48 \mathrm{~h}(\mathrm{E})$ and $72 \mathrm{~h}(\mathrm{~F})$. Data are shown as mean \pm SEM.

$\pm 1.04 \%$ cells when compared to $0.28 \pm 0.03 \%$ cells in reserpine treated cells; and A549Luc: $5.66 \pm 0.27 \%$ cells when compared to $1.13 \pm 0.13$ $\%$ cells in reserpine treated cells). These results were in agreement with previous findings [48-50].

\section{In vitro effects of IMD-0354 on human non-small cell lung CSCs}

IMD-0354, an inhibitor of the NF- $\kappa B$ pathway, was initially developed to inhibit inflammation [51,52], but recently proven to have anticancer properties $[24,53,54]$. Here, we wanted to assess if IMD-0354 also affects CSCs, as indicated by prior screening. A549 cells, when treated with IMD-0354, showed a decrease in SP of CSCs in a dose dependent manner (Figure $4 \mathrm{D}$ ), with an $\mathrm{IC}_{50}$ in the low micromolar range $\left(\mathrm{IC}_{50}=1.0 \mu \mathrm{M}\right)$. Similarly, IMD-0354 decreased SP in A549Luc cells in a concentration dependent manner, with an $\mathrm{IC}_{50}$ in the nanomolar range (Figure $4 \mathrm{E} ; \mathrm{IC}_{50}=410 \mathrm{nM}$ ). Interestingly, A549Luc reveled a somewhat higher sensitivity to IMD-0354 effects on SPs.

Lung CSCs express other stem-like properties. One of them is the ability to grow as 3D spheres or colonies under certain conditions, such as low attachment plates [55]. When human NSCLC cells A549 were grown on low attachment plates, they were able to form spheres of several cells (colonies); however, $1 \mu \mathrm{M}$ IMD-0354 inhibited A549 cells' ability to form such tumor spheres in low attachment plates (Fig. 5A; $45.0 \pm 5.2 \%$ colonies compared to control). Similarly, A549Luc cells treated with $1 \mu \mathrm{M}$ IMD-0354 produced fewer colonies than controls in low attachment plates (Figure $5 \mathrm{~B} ; 9.5 \pm 5.5 \%$ colonies compared to control).

Another CSC trait is their stem-like gene expression profile, including $\mathrm{ABC}$ transporters MDR1 and ABCG2, stem-ness genes Nanog, Oct4 and Sox2, and the anti-apoptotic gene Survivin [55-59]. The expression of these genes was first assessed in whole cell extracts of sorted A549 SP and non-SP cells (Figure 5C). Sorted SP A549 cells expressed higher levels of mdr1, abcg2, oct4, nanog, sox2 and survivin when compared to sorted non-SP A549 cells. When A549Luc and parental A549 were compared, A549Luc expressed a lower level of abcg2 and oct4, and a higher level of sox2, compared with A549 (Figure 5D). Despite those differences, both cell lines, A549 and A549Luc expressed CSCs genes. In addition, the expression of these genes was assessed at the protein level by Western blots of cytosolic (cyt.) and nuclear (nuc.) extracts. A549Luc cells treated with IMD-0354 showed a marked decrease in transcription factors nanog, oct 4 , sox 2 and survivin in the nuclear extract, especially at $1 \mu \mathrm{M}$, indicating a reduction of activity of these proteins and their target transcripts (Figure 5E). Additionally, oct 4 , sox 2 and survivin proteins increased in the cytosolic fraction, indicating a reduction of these transcription factor activities due to subcellular localization. Protein expression of $A B C$ transporters MDR1 and ABCG2 was reduced by $1 \mu \mathrm{M}$ IMD-0354 treatment when compared to controls in the cytosolic and nuclear fractions.

Taking together, these results indicated that IMD-0354 reduced not only SP or dye efflux, but also CSCs subpopulations, including gene 
A

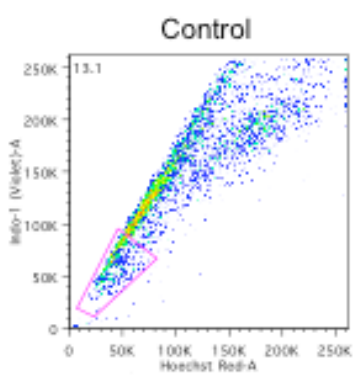

B
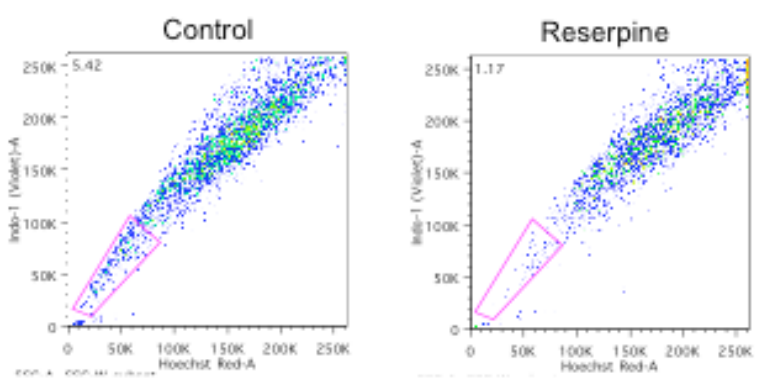

$\mathrm{C}$

A549

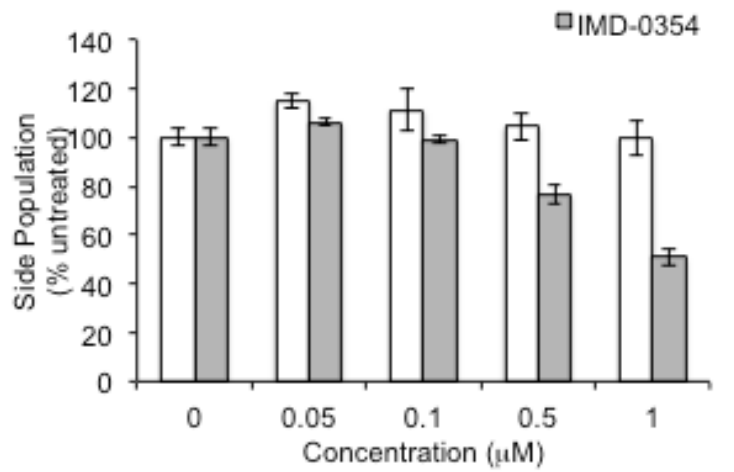

A549

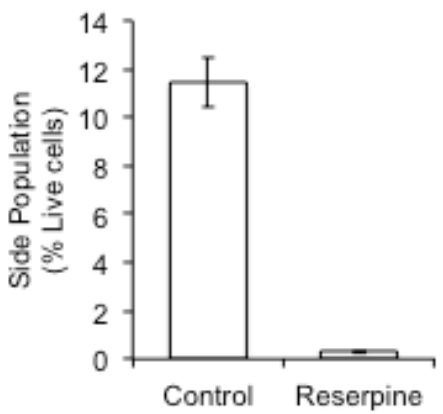

A549Luc

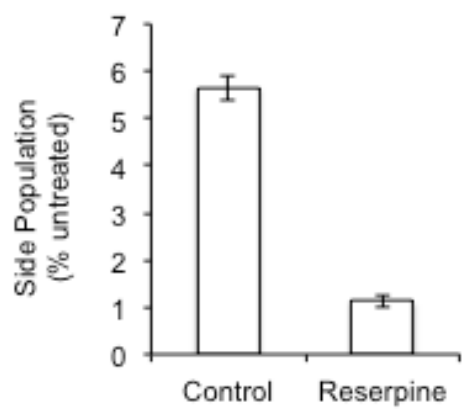

Figure 4: IMD-0354 inhibits side population of CSCs in human NSCLC cells. Side population of CSCs as measured by FACS and Hoechst 33342 dye efflux inhibition by reserpine in A549 (A) and A549Luc (B). Dose curves of IMD-0354 effects on side population of CSCs were assessed in A549 (C) and A549Luc (D). Data are shown as mean \pm SEM.

expression and tumor-sphere formation capability in both cancer cell lines.

\section{In vitro effects of IMD-0354 on human NSCLC cells}

In addition to the IMD-0354 effects on CSCs, we wanted to know if this compound could also affect non-CSCs or bulk tumor cells. First, human NSCLC A549Luc cells were treated with IMD-0354 and their viability assessed by the MTT assay (Figuress $5 \mathrm{~F}-\mathrm{H}$ ). These cells revealed low resistance to IMD-0354 at 24, 48 and $72 \mathrm{~h}\left(\mathrm{IC}_{50}=7.4,2.4\right.$ and $2.2 \mu \mathrm{M}$, respectively).
We then determined whether the cytotoxic effect of IMD-0354 correlated with an increase in apoptosis. To this end, A549Luc cells treated with IMD-0354 were stained with Annexin V-FITC and analyzed by FACS to detect apoptotic cells (Figure 5I). IMD-0354 was able to increase apoptosis of Annexin V-FITC positive cells when treated with $100 \mathrm{nM}$ to $1 \mu \mathrm{M}$ IMD-0354: apoptosis was increased 16-32 $\%$ compared to controls (increase from $32.4 \%$ in controls to $37.4-42.6$ $\%$ of viable cells in IMD-0354 treated cells; P-value $(100 \mathrm{nM})=0.0361$; $\mathrm{P}$-value $(300 \mathrm{nM})=0.0075$; and P-value $(1 \mu \mathrm{M})=0.0037)$, in agreement with the apoptotic cell phenotype observed under the microscope 
Citation: Gomez-Cabrero A, Wrasidlo W, Reisfeld RA (2013) NF-kB Inhibitor IMD-0354 Targets Human Non-Small Cell Lung Cancer Stem Cells and Combined with Chemotherapy Reduces Multidrug Resistance. J Cancer Sci Ther 5: 300-312. doi:10.4172/1948-5956.1000220

A

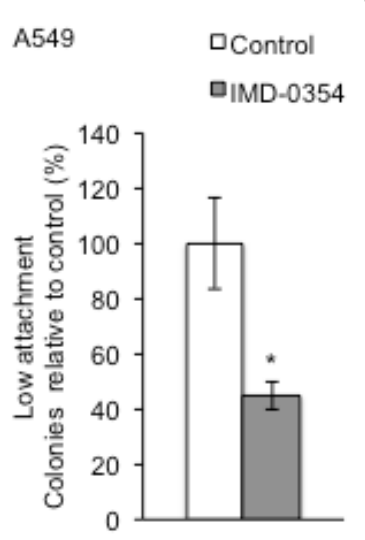

C

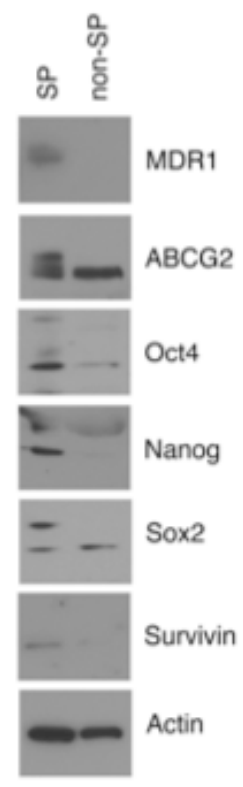

E

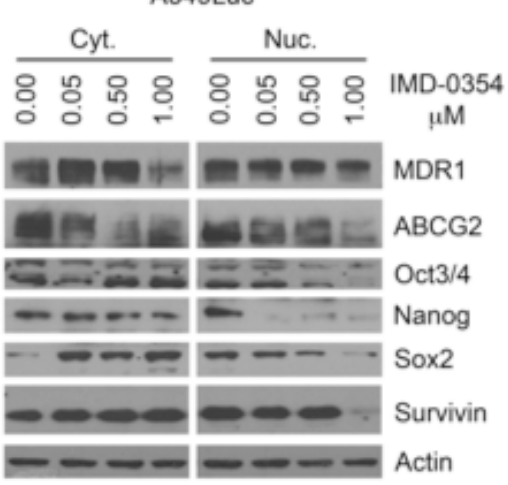

D
$\mathbf{F}$

A549Luc $\quad$ Control

ㅁIMD-0354
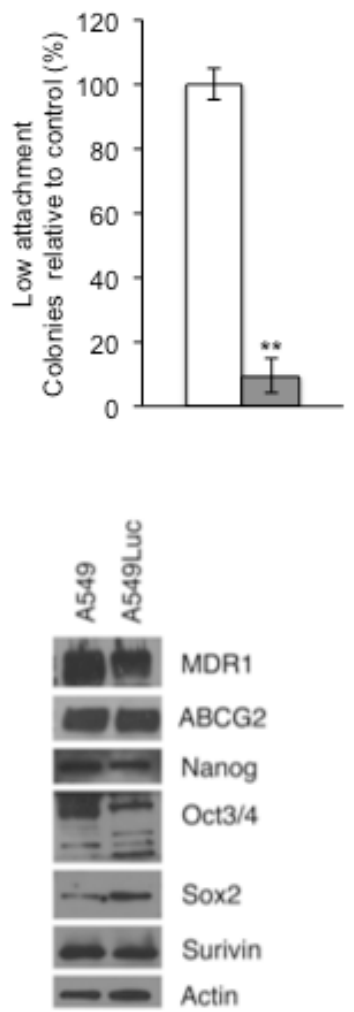

G

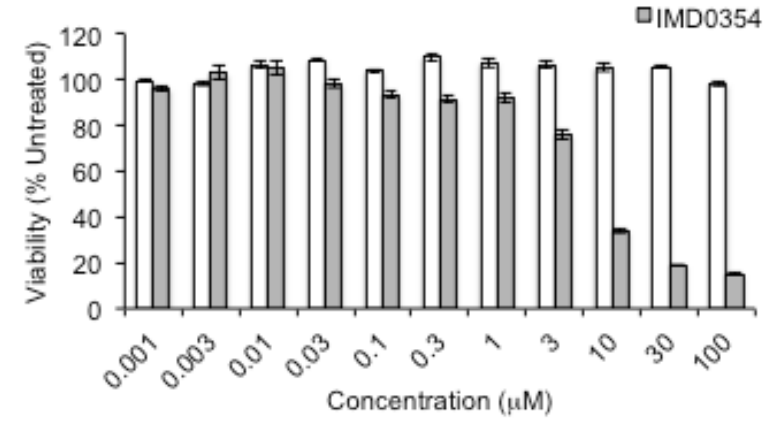

A549Luc (48 h)

$\square$ Control

ㅁIMD0354

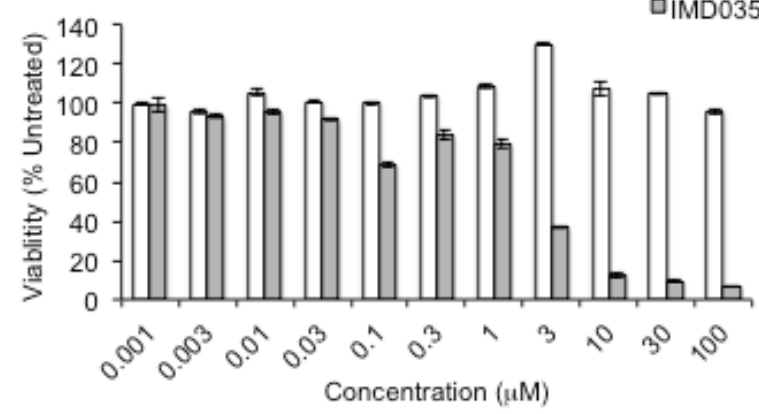

$$
\text { H A549Luc (72 h) aControl }
$$

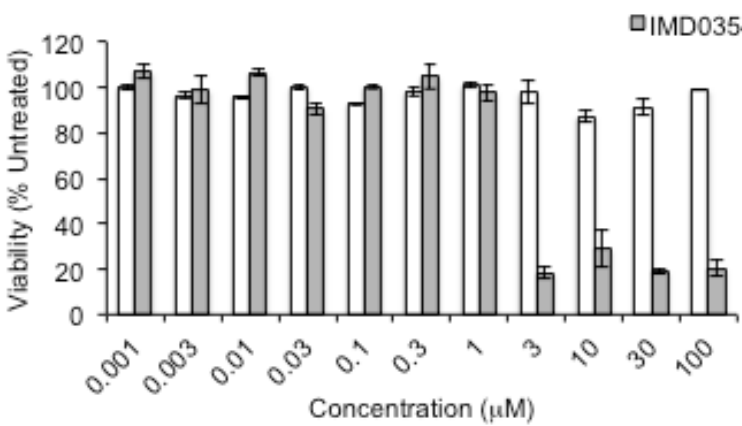

I

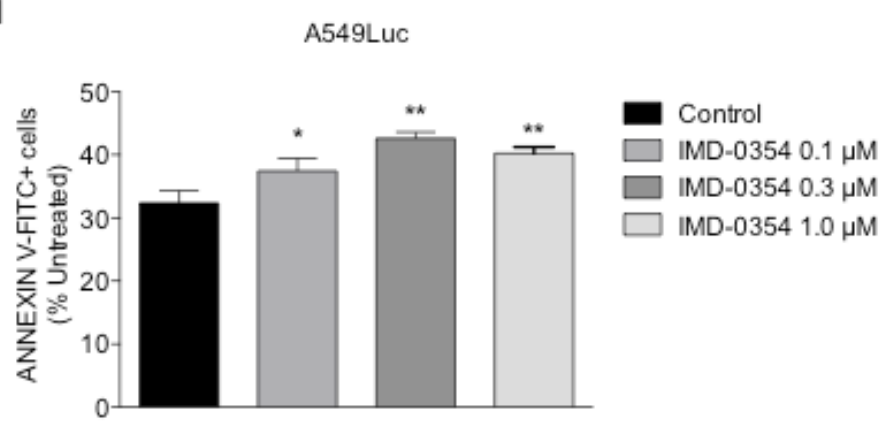

Figure 5: Effects of IMD-0354 on bulk human NSCLC cells and CSCs. Number of colony formation is shown in low attachment plates of A549 (A) and A549Luc (B) treated with $1 \mu \mathrm{M}$ IMD-0354. (C) Western blots are shown of CSCs gene expression in sorted cells of side population (SP) and non-side population (non-SP). (D) A comparison of CSCs gene expression is made between A549 and A549Luc. (E) Western blot of CSCs gene expression in cytosolic and nuclear extracts from A549Luc cells treated with IMD-0354. Viability of A549Luc cells was assessed by MTT assay after treatment with IMD-0354 for $24 \mathrm{~h}$ (F), $48 \mathrm{~h}(\mathrm{G})$ and $72 \mathrm{~h}(\mathrm{H})$. Apoptotic cells are indicated as Annexin V-FITC+ cells as analyzed by FACS of A549Luc cells treated with IMD-0354 (I). Data are shown as mean \pm SEM. ${ }^{*}$ P-value $<0.05$; ${ }^{* *}$ P-value $<0.01$. 
Citation: Gomez-Cabrero A, Wrasidlo W, Reisfeld RA (2013) NF-kB Inhibitor IMD-0354 Targets Human Non-Small Cell Lung Cancer Stem Cells and Combined with Chemotherapy Reduces Multidrug Resistance. J Cancer Sci Ther 5: 300-312. doi:10.4172/1948-5956.1000220

during cytotoxic screening. Therefore, IMD-0354 had a cytotoxic effect on both A549 parental and firefly luciferase expressing cells, partially due to induction of apoptosis.

\section{In vitro effects of combination therapy with IMD-0354 plus chemotherapeutic drugs}

Since CSCs have a higher capability to efflux dyes and drugs, we hypothesized that by targeting CSCs one should also be able to inhibit MDR and increase sensitivity to chemotherapeutic agents. Therefore, we analyzed cell viability by the MTT assay after treatment with a combination therapy of IMD-0354 and chemotherapeutics. Human NSCLC cells A549Luc were treated with Dox alone or Dox plus $1 \mu \mathrm{M}$ IMD-0354 and their viability assessed by MTT (Figure 6A). Although in the nanomolar range of Dox $(1 \mathrm{nM}-1 \mu \mathrm{M})$ IMD-0354 was not able to increase its cytotoxicity (viability $60-80 \%$ ), the NF- $\mathrm{kB}$ inhibitor had an additive effect on reducing viable cells together with Dox in the micromolar range. In fact, at 10-100 $\mu \mathrm{M}$ Dox, viability was reduced from $35-60 \%$ to $10-15 \%$ by co-treatment with IMD-0354. However, this additive cytotoxic effect of IMD-0354 in A549Luc cells was not limited to a combination with Dox, but was also found in combination with Mtx. A549Luc cells treated with a combination of IMD-0354 and Mtx, resulted in a clear reduction in viability compared to Mtx alone, especially at higher concentrations (Figure $6 \mathrm{~B}$ ): $\mathrm{IC}_{50}$ was reduced nearly two orders of mangnitude, from 69 to $0.3 \mu \mathrm{M}$, and the additive cytotoxicity was maximal in the $10-100 \mu \mathrm{M}$ range. In the case of combination treatment with IMD-0354 and Cis, the added cytotoxicity was more modest, but consistent from nanomolar to high micromolar ranges of Cis (Figure 6C).

Interestingly, when A549Luc cells were treated with Dox alone or in combination with $1 \mu \mathrm{M}$ IMD-0354 under hypoxia (Figure 6D), IMD-0354 had the highest additive cytotoxic effect at a nanomolar range of Dox $(1 \mathrm{nM}-3 \mu \mathrm{M})$, decreasing viability an extra $20 \%$. All together, these results indicated that IMD-0354 could improve the effectiveness of chemotherapeutic agent over bulk tumor cells as well, even under hypoxia.

\section{In vitro targeted drug delivery}

One common detrimental effect of free chemotherapeutic systemic delivery in vivo is its toxic side effect on healthy organs. For example, Dox is known for its high cardiac toxicity among off target effects [60]. To overcome this problem, a targeted nanoparticle (tNP) delivery method has been previously developed in our laboratory that allows for safe in vivo Dox delivery to the TME with little or no toxic side effects [27]. Such nanoparticles specifically target cells expressing legumain in their plasma membranes, which is a common property of the TME, especially under hypoxic conditions $[27,31,33,41]$. However, before a combination therapy of IMD-0354 plus Dox could be critically tested in animal models, legumain expression and tNP drug delivery had to be assessed in vitro.

Legumain protein expression was confirmed by Western blot of whole lysates from A549Luc cells (Figure 6E; legumain band density relative to actin band density: under normoxia 0.96 vs hypoxia 1.40). Legumain expression induction and translocation to the extracellular portion of the plasmatic membrane can be induced by hypoxia, either by reducing oxygen content or treating cells with $100 \mu \mathrm{M} \mathrm{CoCl}_{2}$ for 24 h. Thus, A549Luc cells were treated with $\mathrm{CoCl}_{2}$ and their extracellular, membrane bound legumain analyzed by external immunostaining and FACS (Figure 6F). The treatment mimicking hypoxia with $\mathrm{CoCl}_{2}$ induced the externalization of legumain in A549 cells nearly 2-fold
$(207 \%$ relative to normoxia; $\mathrm{P}$-value $=0.0001)$, in agreement with previous results [27].

In fact, targeted delivery of Dox reduced cell viability in vitro. tNP loaded with Dox (tNP-Dox) had a similar cytotoxic effect on A549Luc cells than free Dox at lower concentrations (0.1-1 $\mu \mathrm{M})$. Interestingly, tNP-Dox was less cytotoxic at higher concentrations (Figure 6G). Together, these results indicated that $\mathrm{tNP}$ could facilitate an effective, safe delivery vehicle for Dox or combination therapy treatment.

To further study that encapsulation in tNPs would not affect the ability of IMD-0354 to reduce SP, the effect of the different tNPs on $\mathrm{SP}$ was studied in vitro. After $24 \mathrm{~h}$ incubation of A549Luc with $\mathrm{CoCl}_{2}$ to induce legumain expression, A549Luc cells were treated with tNPDox, tNP-IMD-0354 or tNP-Dox-IMD-0354 for $24 \mathrm{~h}$ and their SP analyzed by FACS after Hoechst 33342 staining (Figure S1). Compared to this control, treatment of A549Luc cells with tNP-Dox reduced the non-SP population, making the SP of cells as the majority of live cells. Treatment of A549Luc cells with tNP-IMD-0354 produced the opposite effect, reducing only SP cells and leaving non-SP cells alive. The combination treatment of A549Luc cells with tNP-Dox-IMD-0354 reduced both SP and non-SP of live cells although the remaining nonSP cells were relatively more abundant than SP cells. Therefore, Dox and IMD-0354 encapsulation into tNPs did not affect their ability to reduce non-SP of bulk tumor cells and SP of CSCs, respectively.

\section{IMD-0354 alone or combined with doxorubicin reduces human NSCLC tumor burden in vivo}

To simulate aggressive or advanced NSCLC cancer, mice were inoculated with human NSCLC cells. To be able to easily follow tumor burden and metastasis, firefly luciferase expressing A549 (A549Luc) cells were used in order to identify tumor cells by non-invasive in vivo imaging. Thus, A549Luc cells were injected intravenously into female athymic nude mice (day 0 ) to simulate aggressive or advanced NSCLC. Then, tNP-Dox, tNP-IMD-0354 or tNP-Dox-IMD-0354 were administrated intravenously every 3 days, and tumor cells detected by their bioluminescence. In this experimental mouse metastasis model, A549Luc cells produced tumors and metastasis in a variety of organs, especially in lungs (Figure 7A; bioluminescence intensity was indicated in pseudocolor as total flux normalized units photons/

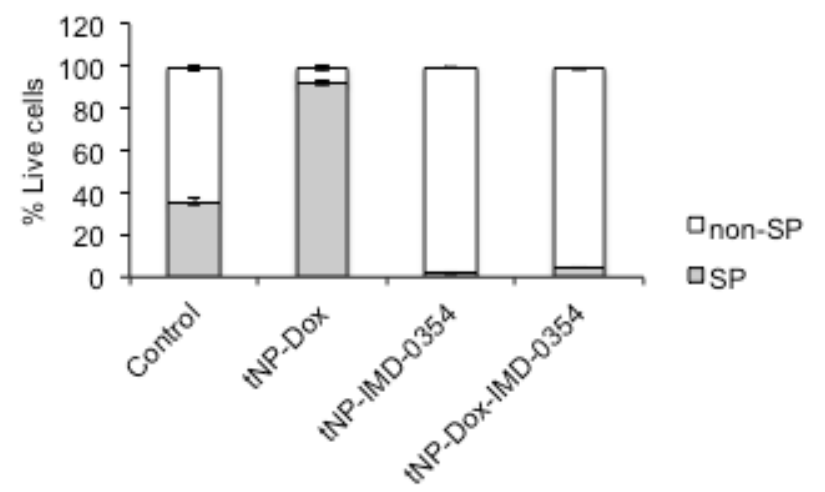

Figure S1: Effects of drug loaded tNPs in vitro on side population of CSCs. Both side population (SP) of CSCs and non-side population (non-SP) of bulk cancer cells were measured by FACS and Hoechst 33342 dye efflux in A549Luc cells after treatment in vitro with tNP-Dox, tNP-IMD-0354 or tNPDox-IMD-0354, and compared to control. Data are shown as mean \pm SEM. 
Citation: Gomez-Cabrero A, Wrasidlo W, Reisfeld RA (2013) NF-kB Inhibitor IMD-0354 Targets Human Non-Small Cell Lung Cancer Stem Cells and Combined with Chemotherapy Reduces Multidrug Resistance. J Cancer Sci Ther 5: 300-312. doi:10.4172/1948-5956.1000220

A

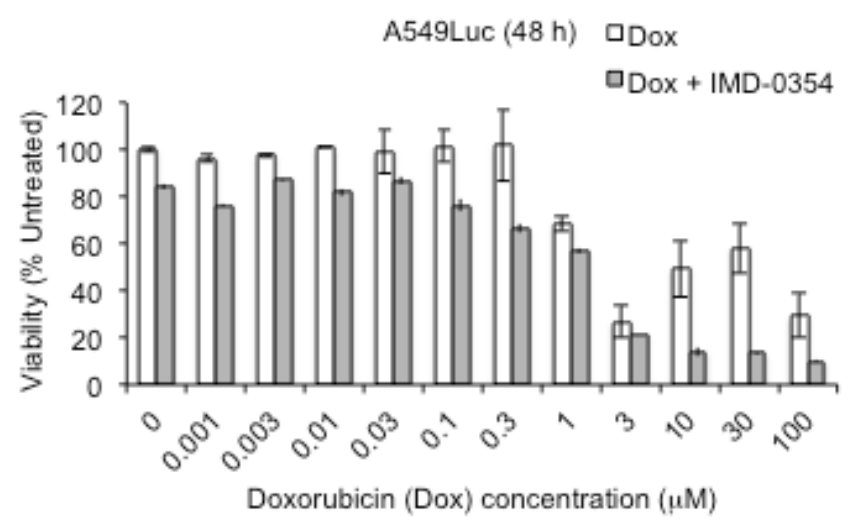

B

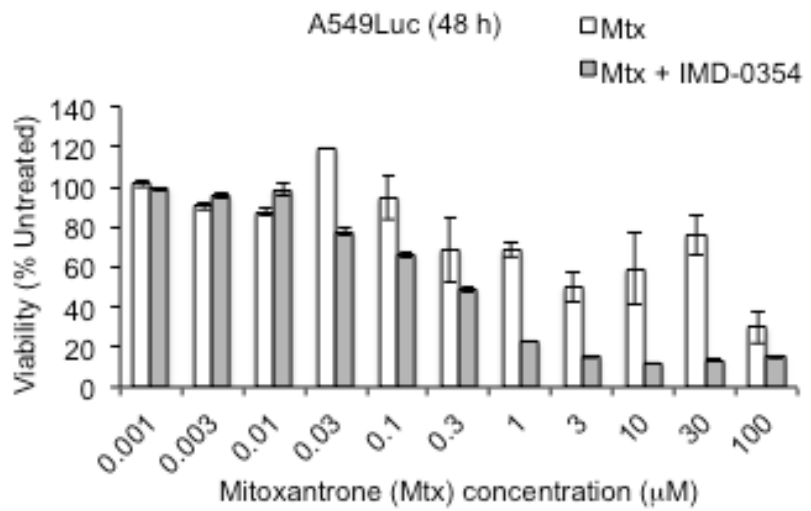

C A549Luc (48 h)

\section{$\square$ Cis}

$\square$ Cis + IMD-0354

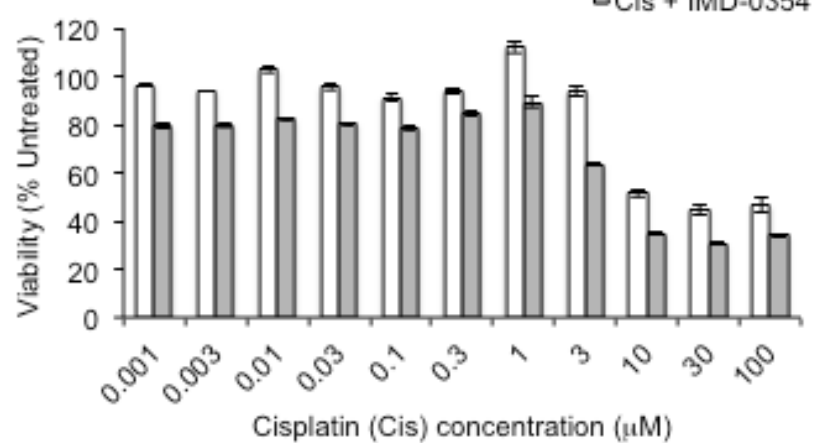

D

A549Luc (hypoxia) DDox

口Dox + IMD-0354

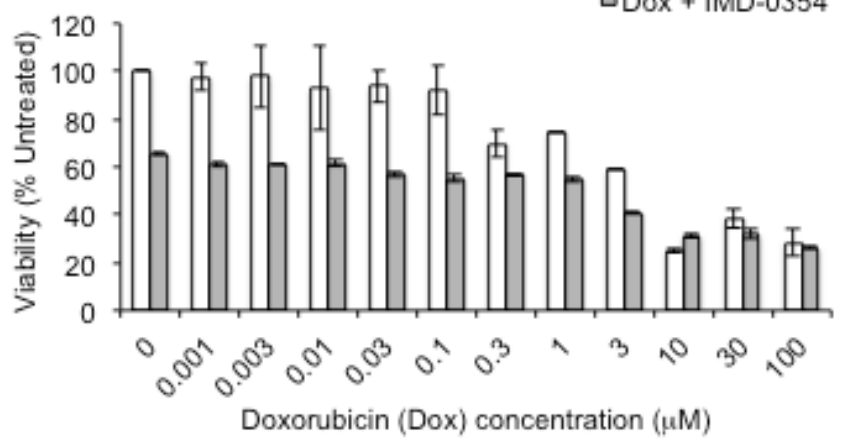

E

A549Luc

$\mathbf{F}$

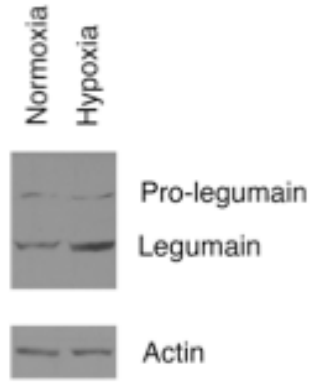

G

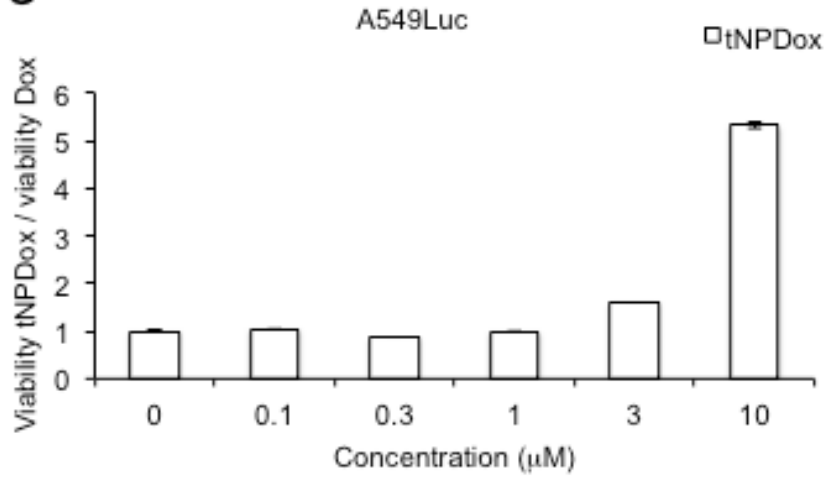

Figure 6: Combination therapy and tNP drug delivery in vitro. Viability of A549Luc cells was assessed by MTT assay after treatment with doxorubicin alone or in combination with IMD-0354 for $48 \mathrm{~h}(\mathrm{~A})$. Viability of A549Luc cells was measured by the MTT assay after treatment with mitoxantrone alone or in combination with IMD-0354 for $48 \mathrm{~h}(\mathrm{~B})$. Viability of A549Luc cells was also evaluated by the MTT assay after treatment with cisplatin alone or in combination with IMD-0354 for $48 \mathrm{~h}$ (C). Viability of A549Luc cells was determined by the MTT assay after treatment with doxorubicin alone or in combination with IMD-0354 for $48 \mathrm{~h}$ under hypoxia (D). Induction of legumain expression under hypoxia was assessed by Western blots of whole cell lysates of A549Luc cells (E). Surface extracellular display of legumain on A549Luc cells was established by FACS under normoxia and hypoxia (F). Relative viability of A549Luc cells assessed by the MTT assay after treatment with tNP-Dox for $48 \mathrm{~h}$ and compared to viability after treatment with free Dox $(\mathrm{G})$. Data are shown as mean $\pm \mathrm{SEM}$. ${ }^{* *} \mathrm{P}-\mathrm{value}<0.005$. 
second). At day 11, no significant differences in bioluminescence were observed between controls and tNP-Dox treated mice. Interestingly, after only 4 doses of tNP treatment, a statistical significant reduction in tumor burden (bioluminescence intensity) was achieved by tNP-DoxIMD-0354 treatment compared to control (Figure $7 \mathrm{~B} ; 3.53 \times 10^{5} \mathrm{p} / \mathrm{s}$ versus $7.12 \times 10^{5} \mathrm{p} / \mathrm{s} ; \mathrm{P}$-value $=0.0256$ ). The reduction in tumor burden by tNP containing IMD-0354 proved also statistically significant when compared to control group $\left(3.68 \times 10^{5} \mathrm{p} / \mathrm{s}\right.$ versus $7.12 \times 10^{5} \mathrm{p} / \mathrm{s}$; P-value $=0.0209$ ).

\section{Discussion}

Because the majority of patients diagnosed with NSCLC are unsuitable for surgery, chemotherapy remains the cornerstone of treatment since it can prolong survival with a positive impact on quality of life. However, most patients with advanced NSCLC experience cancer progression after 3-6 months of first-line chemotherapy, and approximately $40 \%$ of them develop progressive disease during treatment [61]. Here, we showed that human NSCLC cell lines A549 and A549Luc showed little resistance to common chemotherapeutics such as Dox, Mtx and Cis.

MDR and cancer recurrence are the main reasons why many lung cancer patients die despite the efforts of chemotherapy treatment. A recent hypothesis placed CSCs as the culprit of such drug resistance and recurrence, in addition to cancer progression and metastasis. Therefore, since CSCs possess unique capabilities for proliferation, tumorigenesis and chemoresistance, they are interesting therapeutic targets for prevention of cancer recurrence. The fact that CSCs are found in both human and murine cancer cells, as well as in patients' cancer tissue samples of most cancer types, makes this cell type a very attractive target for NSLCLC treatment, and with a potential to be effective also in other types of cancer. Here, we demonstrated that human NSCLC cell lines A549 and A549Luc present a side population of CSCs after staining with Hoechst 33342. These CSCs also exhibited other characteristic stem cell-like properties: tumor-sphere formation in low attachment plates, and expression of Oct4, Nanog, Sox 2 and Survivin stem-ness related genes. Interestingly, SP of CSCs in A549Luc cells increased under hypoxia, similarly to what has been found in ovarian and prostate cancer $[62,63]$.

We previously discovered that IMD-0354 could reduce SP of CSCs in breast and lung cancer cell lines, using a functional assay based on CSCs general drug efflux ability instead of cell surface markers, which are highly variable among cell lines or tissue samples (unpublished data). IMD-0354 is a NF- $\kappa B$ inhibitor with anti-inflammatory activity [51,52] and cytostatic effects on some cancer cells [64]. Here we demonstrated its effect on human lung CSCs, in addition to its effect on human lung bulk tumor cells. IMD-0354 was able to reduce SP of CSCs, tumorsphere formation and stem-like gene expression in two human NSCLC cell lines, indicating that IMD-0354 not only reduced drug efflux, but also stem-ness of this subpopulation of cells. Similarly, when other NF$\kappa \mathrm{B}$ pathway inhibitors were used, breast CSCs population decreased [65]. IMD-0354's ability to reduce SP of CSCs was not impaired by its encapsulation into tNP, either alone or in combination with Dox.

In addition to its ability to decrease human lung CSCs, IMD-0354 also decreased viability of human lung bulk tumor cells, similarly to what has been reported for other types of cancer [64], and induced

A

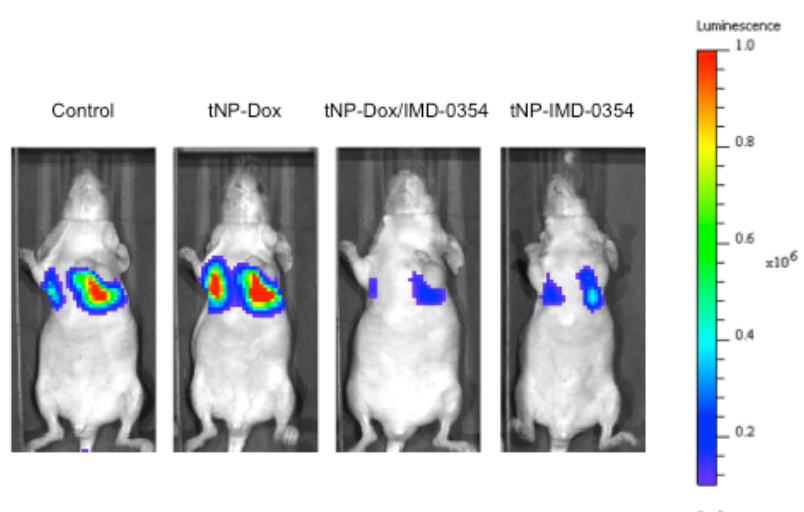

B

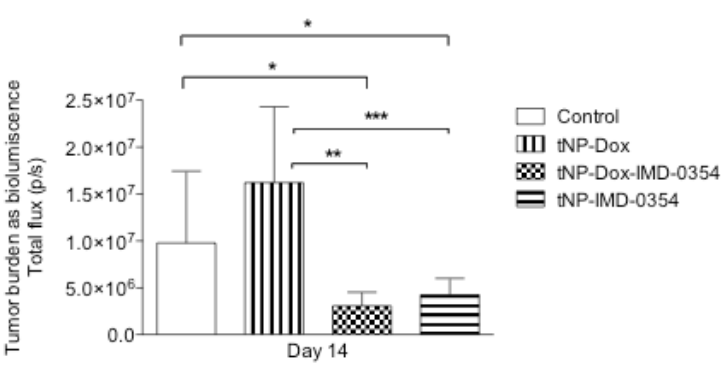

Figure 7: In vivo drug delivery of combination therapy encapsulated into tNPs. Mice bearing experimentally metastatic A549Luc tumors were treated either with tNP-Dox, tNP-IMD-0354 or tNP-Dox-IMD-0354. Tumor burden was measured by in vivo non-invasive imaging of A549Luc cells expressing firefly luciferase afte intraperitoneal luciferin injection. Tumor bioluminescence intensity was plotted in pseudocolor over back/white photographs (A) and quantified as total flux in photons/ seconds. Data are shown as mean \pm SEM. ${ }^{*}$ P-value $<0.05$. 
apoptotic cell death. IMD-0354 further showed additive cytotoxic effect in combination with other common chemotherapeutic drugs such as Dox and Mtx at high micromolar concentrations under normoxia. However, under hypoxia, IMD-0354 increased Dox cytotoxic effect in the nanomolar range. This interesting hypoxia-dependent effect suggests that in healthy tissues, where usually there is a normal level of oxygen, IMD-0354 will not increase the already low cytotoxicity of Dox, since concentrations greater than $1 \mu \mathrm{M}$ are not feasible in patients; but it is in the TME, characterized by hypoxia [29,31], where IMD-0354 will have a synergistic effect with Dox, in the nanomolar range, the concentrations at which chemotherapeutics are usually administered to patients. This dual effect has the potential to contribute to a higher toxicity only in the TME while helping to protect the remaining of the body from off target toxicity. It also suggests that IMD-0354 could facilitate the anti-cancer effect of Dox and that it could be achieved at a lower concentration, making it possible to reduce cardiac toxicity.

For in vivo treatment of human xenograft of NSCLC in athymic mice, we used tNPs to safely direct chemotherapeutic agents to the TME, as we previously did for monotherapy with Dox to treat murine breast cancer in a syngeneic model [27]. Importantly, the use of the same type of tNPs for IMD-0354 should improve pharmacokinetics and pharmacodynamics of a combination therapy of Dox and IMD0354. For this purpose, mice were intravenously injected with firefly luciferase expressing human NSCLC cells (A549Luc), which could be detected by their bioluminescence in a non-invasive way. In fact, tumors rapidly seeded in the lungs and grew resembling the aggressive progression found in many NSCLC patients. Fourteen days after human xenograft implantation, tumor progression and metastases were evident and extensive in control animals. tNP-Dox treated animals showed a similar effect in human NSCLC progression compared to controls. This treatment was not only inefficient, but it seemed to slightly increase tumor progression. The fact that these mice did not suffer from acute toxicity from Dox suggests that tNPs indeed protects healthy organs from Dox toxicity, since a similar dose of free Dox was reported to be extremely toxic in mice [27]. In this case, tNP-Dox lack of efficacy was most likely due to tumor repopulation. This resulted most likely from lung CSCs activation after depletion of bulk cancer cells by Dox toxicity, particularly since free Dox and tNP-Dox were equivalently efficient in vitro at nanomolar concentrations attainable in vivo. In the process, CSCs survive due to their intrinsic MDR, and bulk tumor cells are selected with higher resistance to Dox. This correlates with cancer recurrence observed in NSCLC patients and other animal studies of tumor repopulation from CSCs.

After just five doses of tNP-IMD-0354, tumor burden was significantly reduced when compared to controls and tNP-Dox treated mice. Treatment with the combination therapy tNP-DoxIMD-0354 resulted in equally or greater reduction in tumor burden, although no differences were observed between tNP-IMD-0354 and the combination therapy. The A549Luc cells used in these animal experiments were equally sensitive to all the chemotherapeutic agents used, including IMD-0354, compared to the parental A549 cells used in in vitro experiments. Therefore, the cloning of firefly luciferase in this cell line did not significantly change its in vitro behavior, and this is not likely to differ in vivo. It is interesting that tNP-IMD-0354 used as a single therapy reduced tumor burden is in agreement with our in vitro data, where IMD-0354 reduced both lung CSCs and bulk tumor cells. Furthermore, tNP-Dox-IMD-0354 biotherapy was able to further reduce tumor burden, despite the fact that tNP-Dox produced a higher tumor burden. This result was expected since our in vitro data showed a synergistic effect between Dox and IMD-0354, especially under hypoxia.
Both tNP-IMD-0354 and the combination therapy tNP-DoxIMD-0354 were able to significantly reduce tumor bioluminescence in our challenging, fast growing metastatic model of human NSCLC. Such a decrease in A549Luc cells accounts for both the number of metastases and tumor size, since bioluminescence is quantified for the whole mouse body and integrates both parameters. Importantly, this efficacy was achieved without decreasing body weight (data not shown), one of the first parameters to be affected by acute toxicity. This indicates a safe drug delivery that is in agreement with more extensive analysis of tNPs safety in mouse models of breast cancer analyzed previously by our group of investigators [27].

In summary, long-term survival and prognosis of patients with metastatic or recurrent NSCLC still remains a major concern, and better tools are needed for the effective treatment of this disease, particularly to provide some hope for over 150,000 Americans that are expected to succumb to lung cancer each year [1]. CSCs, with their ability to resist chemotherapeutic agents and other stress factors, including their repopulation capabilities, are probably a major cause of MDR and cancer recurrence. Importantly, a combination therapy against CSCs and bulk tumor cells, using IMD-0354 and Dox, showed an effective reduction in tumor burden within just 5 doses treating a very aggressively growing human NSCLC xenograft in a mouse model. Furthermore, monotherapy with IMD-0354 proved very effective in the same fast progressing human NSCLC tumor model. These findings have several implications. First, targeting CSCs, alone or in combination therapies, could decrease MDR and cancer recurrence. Second, encapsulation of chemotherapeutic agents into nanoparticles allows for higher doses, and higher efficacy, and thus, reducing toxic side effects of these chemotherapeutic agents and synchronizing the pharmacokinetics and pharmacodynamics properties of different drugs when used in combination therapy. Third, legumain-directed tNPs can specifically target chemotherapeutic agents towards the tumor and its hypoxic TME, allowing for higher drug doses locally where they are most needed. Therefore, this novel targeted combination therapy could be an excellent candidate for clinical trials on NSCLC resulting in more effective and safe treatment of this cancer and an acceptable prognosis of these patients.

\section{Acknowledgements}

The authors thank Giang Nguyen for technical support, Kathy Cairns for administrative assistance and $\mathrm{Dr}$. Brunhilde Felding for facilitating the use of he in vivo imaging IVIS system. The A549Luc firefly luciferase expressing human NSCLC cell line was kindly provided by Dr. Edward Graves (Stanford University School of Medicine). Non-invasive in vivo imaging of mice was facilitated by $\mathrm{Dr}$. Brunhilde Felding (The Scripps Research Institute).

This work was supported in part by NIH grant 1R01CA134364 and TRDRP grant 19XT-0051

\section{References}

1. Siegel R, Naishadham D, Jemal A (2013) Cancer statistics, 2013. CA Cancer J Clin 63: 11-30

2. Ailles LE, Weissman IL (2007) Cancer stem cells in solid tumors. Curr Opin Biotechnol 18: 460-466.

3. Dean $M$ (2009) ABC transporters, drug resistance, and cancer stem cells. $J$ Mammary Gland Biol Neoplasia 14: 3-9.

4. Eramo A, Lotti F, Sette G, Pilozzi E, Biffoni M, et al. (2008) Identification and expansion of the tumorigenic lung cancer stem cell population. Cell Death Differ 15: 504-514

5. Ho MM, Ng AV, Lam S, Hung JY (2007) Side population in human lung cance cell lines and tumors is enriched with stem-like cancer cells. Cancer Res 67 : 4827-4833.

6. Tirino V, Desiderio V, Paino F, De Rosa A, Papaccio F, et al. (2013) Cancer 
Citation: Gomez-Cabrero A, Wrasidlo W, Reisfeld RA (2013) NF-KB Inhibitor IMD-0354 Targets Human Non-Small Cell Lung Cancer Stem Cells and Combined with Chemotherapy Reduces Multidrug Resistance. J Cancer Sci Ther 5: 300-312. doi:10.4172/1948-5956.1000220

stem cells in solid tumors: an overview and new approaches for their isolation and characterization. FASEB J 27: 13-24.

7. Baccelli I, Trumpp A (2012) The evolving concept of cancer and metastasis stem cells. J Cell Biol 198: 281-293.

8. Perona R, López-Ayllón BD, de Castro Carpeño J, Belda-Iniesta C (2011) A role for cancer stem cells in drug resistance and metastasis in non-small-cell lung cancer. Clin Transl Oncol 13: 289-293.

9. Kitamura H, Okudela K, Yazawa T, Sato H, Shimoyamada H (2009) Cancer stem cell: implications in cancer biology and therapy with special reference to lung cancer. Lung Cancer 66: 275-281.

10. Travis WD (2002) Pathology of lung cancer. Clin Chest Med 23: 65-81, viii.

11. Leung EL, Fiscus RR, Tung JW, Tin VP, Cheng LC, et al. (2010) Non-small cell lung cancer cells expressing CD44 are enriched for stem cell-like properties. PLoS One 5: e14062.

12. Li F, Zeng $H$, Ying $K$ (2011) The combination of stem cell markers CD133 and ABCG2 predicts relapse in stage I non-small cell lung carcinomas. Med Oncol 28: $1458-1462$

13. Vinogradov S, Wei $X$ (2012) Cancer stem cells and drug resistance: the potential of nanomedicine. Nanomedicine (Lond) 7: 597-615.

14. Nagler C, Zänker KS, Dittmar T (2011) Cell Fusion, Drug Resistance and Recurrence CSCs. Adv Exp Med Biol 714: 173-182.

15. Ogawa K, Yoshioka Y, Isohashi F, Seo Y, Yoshida K, et al. (2013) Radiotherapy targeting cancer stem cells: current views and future perspectives. Anticancer Res 33: 747-754.

16. Levina V, Marrangoni AM, DeMarco R, Gorelik E, Lokshin AE (2008) Drugselected human lung cancer stem cells: cytokine network, tumorigenic and metastatic properties. PLoS One 3: e3077.

17. Eramo A, Haas TL, De Maria R (2010) Lung cancer stem cells: tools and targets to fight lung cancer. Oncogene 29: 4625-4635.

18. Tirino V, Camerlingo R, Franco R, Malanga D, La Rocca A, et al. (2009) The role of CD133 in the identification and characterisation of tumour-initiating cells in non-small-cell lung cancer. Eur J Cardiothorac Surg 36: 446-453.

19. Akunuru S, James Zhai Q, Zheng Y (2012) Non-small cell lung cancer stem/ progenitor cells are enriched in multiple distinct phenotypic subpopulations and exhibit plasticity. Cell Death Dis 3: e352.

20. Onai Y, Suzuki J, Kakuta T, Maejima Y, Haraguchi G, et al. (2004) Inhibition of IkappaB phosphorylation in cardiomyocytes attenuates myocardial ischemia/ reperfusion injury. Cardiovasc Res 63: 51-59.

21. Ling J, Kumar R (2012) Crosstalk between NFkB and glucocorticoid signaling: a potential target of breast cancer therapy. Cancer Lett 322: 119-126.

22. Berenson JR, Ma HM, Vescio R (2001) The role of nuclear factor-kappaB in the biology and treatment of multiple myeloma. Semin Oncol 28: 626-633.

23. Beinke S, Ley SC (2004) Functions of NF-kappaB1 and NF-kappaB2 in immune cell biology. Biochem J 382: 393-409.

24. Tanaka A, Konno M, Muto S, Kambe N, Morii E, et al. (2005) A novel NFkappaB inhibitor, IMD-0354, suppresses neoplastic proliferation of human mast cells with constitutively activated c-kit receptors. Blood 105: 2324-2331.

25. Octavia Y, Tocchetti CG, Gabrielson KL, Janssens S, Crijns HJ, et al (2012) Doxorubicin-induced cardiomyopathy: from molecular mechanisms to therapeutic strategies. J Mol Cell Cardiol 52: 1213-1225.

26. Airoldi M, Amadori D, Barni S, Cinieri S, De Placido S, et al. (2011) Clinica activity and cardiac tolerability of non-pegylated liposomal doxorubicin in breast cancer: a synthetic review. Tumori 97: 690-692.

27. Liao D, Liu Z, Wrasidlo W, Chen T, Luo Y, et al. (2011) Synthetic enzyme inhibitor: a novel targeting ligand for nanotherapeutic drug delivery inhibiting tumor growth without systemic toxicity. Nanomedicine 7: 665-673.

28. Liao D, Liu Z, Wrasidlo WJ, Luo Y, Nguyen G, et al. (2011) Targeted therapeutic remodeling of the tumor microenvironment improves an HER-2 DNA vaccine and prevents recurrence in a murine breast cancer model. Cancer Res 71 : 5688-5696.

29. 29. Hanahan D and Weinberg RA (2000) The hallmarks of cancer. Cell 100: $57-70$
30. Luo Y, Zhou H, Krueger J, Kaplan C, Lee SH, et al. (2006) Targeting tumorassociated macrophages as a novel strategy against breast cancer. J Clin Invest 116: 2132-2141.

31. Hanahan D, Weinberg RA (2011) Hallmarks of cancer: the next generation Cell 144: 646-674.

32. Gawenda J, Traub F, Lück HJ, Kreipe H, von Wasielewski R (2007) Legumain expression as a prognostic factor in breast cancer patients. Breast Cancer Res Treat 102: 1-6.

33. Wang L, Chen S, Zhang M, Li N, Chen Y, et al. (2012) Legumain: a biomarke for diagnosis and prognosis of human ovarian cancer. J Cell Biochem 113 2679-2686.

34. Ohno Y, Nakashima J, Izumi M, Ohori M, Hashimoto T, et al. (2013) Association of legumain expression pattern with prostate cancer invasiveness and aggressiveness. World J Urol 31: 359-364.

35. Bajjuri KM, Liu Y, Liu C, Sinha SC (2011) The legumain protease-activated auristatin prodrugs suppress tumor growth and metastasis without toxicity. ChemMedChem 6: 54-59.

36. Liao D, Liu Z, Wrasidlo W, Chen T, Luo Y, et al. (2011) Synthetic enzyme inhibitor: a novel targeting ligand for nanotherapeutic drug delivery inhibiting tumor growth without systemic toxicity. Nanomedicine 7: 665-673.

37. Graves EE, Vilalta M, Cecic IK, Erler JT, Tran PT, et al. (2010) Hypoxia in models of lung cancer: implications for targeted therapeutics. Clin Cancer Res 16: 4843-4852.

38. Goodell MA (2005) Stem cell identification and sorting using the Hoechst 33342 side population (SP). Curr Protoc Cytom Chapter 9: Unit9.

39. Sambrook J (2001) Molecular cloning: A laboratory manual (3th edn), Cold Spring Harbor Laboratory Press.

40. Dignam JD, Lebovitz RM, Roeder RG (1983) Accurate transcription initiation by RNA polymerase II in a soluble extract from isolated mammalian nuclei. Nucleic Acids Res 11: 1475-1489.

41. Gomez-Cabrero A, Comes N, Gonzalez-Linares J, de Lapuente J, Borras M et al. (2005) Use of transduction proteins to target trabecular meshwork cells outflow modulation by profilin I. Mol Vis 11: 1071-1082.

42. Ekici OD, Götz MG, James KE, Li ZZ, Rukamp BJ, et al. (2004) Aza-peptide Michael acceptors: a new class of inhibitors specific for caspases and other clan CD cysteine proteases. J Med Chem 47: 1889-1892.

43. Hood JD, Bednarski M, Frausto R, Guccione S, Reisfeld RA, et al. (2002) Tumor regression by targeted gene delivery to the neovasculature. Science 296: 2404-2407.

44. Giard DJ, Aaronson SA, Todaro GJ, Arnstein P, Kersey JH, et al. (1973) In vitro cultivation of human tumors: establishment of cell lines derived from a series of solid tumors. J Natl Cancer Inst 51: 1417-1423.

45. Wang X, Fu X, Hoffman RM (1992) A patient-like metastasizing model of human lung adenocarcinoma constructed via thoracotomy in nude mice. Anticancer Res 12: 1399-1401.

46. Gariboldi MB, Ravizza R, Riganti L, Meschini S, Calcabrini A, et al. (2003) Molecular determinants of intrinsic resistance to doxorubicin in human cancer cell lines. Int J Oncol 22: 1057-1064.

47. Kawanabe N, Murakami K, Takano-Yamamoto T (2006) The presence of ABCG2-dependent side population cells in human periodontal ligaments. Biochem Biophys Res Commun 344: 1278-1283.

48. Seo DC, Sung JM, Cho HJ, Yi H, Seo KH, et al. (2007) Gene expression profiling of cancer stem cell in human lung adenocarcinoma A549 cells. Mol Cancer 6: 75 .

49. Scharenberg CW, Harkey MA, Torok-Storb B (2002) The ABCG2 transporter is an efficient Hoechst 33342 efflux pump and is preferentially expressed by immature human hematopoietic progenitors. Blood 99: 507-512.

50. Sung JM, Cho HJ, Yi H, Lee CH, Kim HS, et al. (2008) Characterization of a stem cell population in lung cancer A549 cells. Biochem Biophys Res Commun 371: 163-167.

51. Mantovani A (2010) Molecular pathways linking inflammation and cancer. Curr Mol Med 10: 369-373.

52. Sugita A, Ogawa H, Azuma M, Muto S, Honjo A, et al. (2009) Antiallergic and 
Citation: Gomez-Cabrero A, Wrasidlo W, Reisfeld RA (2013) NF-kB Inhibitor IMD-0354 Targets Human Non-Small Cell Lung Cancer Stem Cells and Combined with Chemotherapy Reduces Multidrug Resistance. J Cancer Sci Ther 5: 300-312. doi:10.4172/1948-5956.1000220

anti-inflammatory effects of a novel I kappaB kinase beta inhibitor, IMD-0354, in a mouse model of allergic inflammation. Int Arch Allergy Immunol 148: 186198.

53. Ochiai T, Saito Y, Saitoh T, Dewan MZ, Shioya A, et al. (2008) Inhibition of IkappaB kinase beta restrains oncogenic proliferation of pancreatic cancer cells. J Med Dent Sci 55: 49-59.

54. Uota S, Zahidunnabi Dewan M, Saitoh Y, Muto S, Itai A, et al. (2012) An lîمB kinase 2 inhibitor IMD-0354 suppresses the survival of adult T-cell leukemia cells. Cancer Sci 103: 100-106.

55. Prud'homme GJ, Glinka Y, Toulina A, Ace O, Subramaniam V, et al. (2010) Breast cancer stem-like cells are inhibited by a non-toxic aryl hydrocarbon receptor agonist. PLoS One 5: e13831.

56. Kim RJ, Nam JS (2011) OCT4 Expression Enhances Features of Cancer Stem Cells in a Mouse Model of Breast Cancer. Lab Anim Res 27: 147-152.

57. Hiraga $T$, Ito $S$, Nakamura H (2011) Side population in MDA-MB-231 human breast cancer cells exhibits cancer stem cell-like properties without higher bone-metastatic potential. Oncol Rep 25: 289-296.

58. Kim SY, Kang JW, Song X, Kim BK, Yoo YD, et al. (2013) Role of the IL-6JAK1-STAT3-Oct-4 pathway in the conversion of non-stem cancer cells into cancer stem-like cells. Cell Signal 25: 961-969.
59. Prud'homme GJ (2012) Cancer stem cells and novel targets for antitumor strategies. Curr Pharm Des 18: 2838-2849.

60. Volkova M, Russell R 3rd (2011) Anthracycline cardiotoxicity: prevalence, pathogenesis and treatment. Curr Cardiol Rev 7: 214-220.

61. Passaro A, Cortesi E, de Marinis F (2011) Second-line treatment of non-smallcell lung cancer: chemotherapy or tyrosine kinase inhibitors? Expert Rev Anticancer Ther 11: 1587-1597.

62. Liang D, Ma Y, Liu J, Trope CG, Holm R, et al. (2012) The hypoxic microenvironment upgrades stem-like properties of ovarian cancer cells. BMC Cancer 12: 201.

63. Ma Y, Liang D, Liu J, Axcrona K, Kvalheim G, et al. (2011) Prostate cancer cel lines under hypoxia exhibit greater stem-like properties. PLoS One 6: e29170.

64. Tanaka A, Muto S, Konno M, Itai A, Matsuda H (2006) A new IkappaB kinase beta inhibitor prevents human breast cancer progression through negative regulation of cell cycle transition. Cancer Res 66: 419-426.

65. Mak KK, Wu AT, Lee WH, Chang TC, Chiou JF, et al. (2013) Pterostilbene, a bioactive component of blueberries, suppresses the generation of breast cancer stem cells within tumor microenvironment and metastasis via modulating NFKB/microRNA 448 circuit. Mol Nutr Food Res 57: 1123-1134. 